\title{
ALGUNAS PRECISIONES \\ EN PUNTO AL HISTÓRICO \\ DISTANCIAMIENTO ENTRE LOS \\ ÓRGANOS JURISDICCIONALES \\ Y LA CIUDADANÍA: LA POSITIVA \\ EXPERIENCIA ANGLOSAJONA
}

\section{Luis Rodríguez Ennes}

Professor catedrático de Direito Romano na Universidade de Vigo (Espanha)

ennes@uvigo.es

Los barones ingleses reunidos en Merton en 1236 proclamaron una voce: "nolumus Angliae leges Mutare, quae hueusque usitatae sunt et aprobate". En realidad, este estamento nobiliario no pudo medir el verdadero alcance de su declaración. Es posible que la animadversión contra el emperador, contra el Imperio y contra el Derecho romano hayan jugado en ello su papel ${ }^{1}$. Este voto de confianza en las viejas leyes de Inglaterra fue pronunciado para rechazar en la Isla el sistema de legitimación de los hijos naturales tomado del derecho romanocanónico $^{2}$. Y no sólo en este aspecto de las leyes de familia, sino en los demás campos del Derecho, Inglaterra mantuvo su posición insular, separándose así del Continente por otra frontera más. Este canal de la Mancha de la ciencia jurídica hizo posible la continuidad evolutiva de la Edad Media a la Edad Moderna en el Derecho inglés, que no quedó interrumpido bruscamente -como en Europa continental- por la adopción del Derecho romano, según afirma Vinogradoff ${ }^{3}$.

1 SHERMAN, C.H., "Salient feautures of the reception of Roman Law into the Common Law of England and America", en Boston University Law Review, 183, 1928, p. 189.

2 MAITLAND, F. W., The Constitutions History of England, Cambridge, 1963, p. 53, donde añade: "Both became suspeciously regarded -owing doubtless to the arrogance of the clergy- as but mere instruments to enclave the English people to popes and emperors: hence the efforts made to curtail the authorative influence in England of the roman Laws".

3 VINOGRADOFF, P., Outlines of Historical Jurisprudence, I, Oxford, 1920, p. 30. 
La cultura jurídica occidental aparece dividida -como es sabido- en dos grandes esferas: los países herederos del Derecho romano y de las codificaciones realizadas a semejanza del Corpus Iuris y los países del Derecho casuístico fundamental. En los primeros, el promotor del Derecho es el legislador; mientras que en los segundos, el papel de protagonista corre a cargo de la magistratura; en unos se determina el Derecho descendiendo del principio jurídico al caso particular; en otros se asciende, por el contrario, desde el caso particular el principio jurídico general. Los países de progenie romanística instituyen el Derecho sobre la base de la ley y del espíritu de la ley; las naciones de tradición anglosajona encuentran su fundamento en la vida jurídica y en la naturaleza de cada asunto ${ }^{4}$.

Sin embargo, no es tanta la separación entre estas dos esferas del Derecho para que se abra un abismo entre ellas. Aunque el canal-llamado inglés por los británicossepara la Isla del resto de Europa, sirve también de gran vía de comunicación. La nave del Derecho romano la surca incesantemente y desde hace siglos impide que se cree una fractura incurable entre estas dos magnas culturas jurídicas 5 .

Aún creyendo la existencia de un cierto espíritu común en las dos esferas del Derecho - continental europea y anglosajona- hay dos claros rasgos del sistema jurídico inglés que, al diferir de otros ordenamientos, le imprimieron su carácter distintivo. Puede afirmarse con C.K. Allen ${ }^{6}$ que las principales notas diferenciales del Derecho inglés son:

$1^{\circ}$. - Su continuidad histórica, a la que ya se ha hecho referencia. En realidad no hay ninguna ruptura importante en el desarrollo del sistema jurídico inglés desde la conquista Normanda hasta nuestros días.

$2^{\circ}$. - La importancia de la centralización, pues -desde el siglo XII- los principales tribunales ingleses han tenido su sede en Londres; y los jueces que desde aquella época recorren el país para rendir justicia, eran y siguen siendo jueces del Tribunal del Rey en Londres.

$3^{\circ}$. - La posición de la magistratura, que tiene un grado extraordinario de prestigio y autoridad, no sólo por el número no muy elevado de jueces, sino también por la facultad del juez de crear el Derecho. El clásico Judge made law tiene una enorme transcendencia en el desarrollo de la ciencia jurídica inglesa.

4 ESCUDERO, J.A., "La Historiografía General del Derecho inglés", en Anuario de Historia del Derecho Español, 35, 1965, p. 217 ss.

5 RODRÍGUEZ ENNES, L., "La recepción del Derecho romano en Inglaterra”, en Actas del I Congreso Iberoamericano de Derecho Romano, Granada, 1995, pp. 203 ss.

6 ALLEN, C.K., Law in the Making, $7^{\text {a }}$ ed., Oxford, 1963, p. LXIV. 
$4^{\circ}$. - El elemento laico en el sistema jurídico inglés. A través del jurado, institución de trascendente importancia en Inglaterra, el elemento no profesional desempeña un decisivo papel en el proceso judicial, incidiendo de un modo patente en el lenguaje oral y gestual de todos y cada uno de los intervinientes en el litigio.

Quizá podría decirse que la característica fundamental de las señaladas por C. $\mathrm{K}$. Allen es la primera, pues en realidad muchos de los rasgos del sistema jurídico inglés, e incluso del espíritu nacional, tienen su fundamento en el hecho de que en Inglaterra -a diferencia de los países del Continente europeo- la Edad Media no se separó de la moderna por un profundo corte sino que, por el contrario, se prolonga todavía en el presente. Esta permanencia de la tradición, fácil de apreciar en la vida inglesa actual, ha arraigado con fuerza en la organización judicial. Efectivamente, en aquellos países adscritos al sistema denominado "romano-germánico", que no cabe circunscribir desde un punto de vista geográfico al Continente europeo, sino que debe extenderse a todas sus antiguas colonias que, tras la emancipación, siguen formando parte de la misma familia jurídica que sus respectivas metrópolis ${ }^{7}$, se observa la existencia de una judicatura incardinada plenamente en la estructura burocrática del Estado, una marginación del elemento laico en la administración de justicia y un Derecho cuya fuente normativa es básicamente la Ley. Lógico colorario de todo ello lo constituye la omnipresencia de un Derecho adjetivo escasamente flexible y, por ende, inspirador de un procedimiento lento, farragoso y redactado en un lenguaje esotérico, ininteligible para el común de los ciudadanos. Por el contrario, en los países del Common Law la judicatura goza de una independencia plena del poder político y el hecho de que, en punto a su consideración social, ocupe la cima de los honores ${ }^{8}$, no obsta en modo alguno para

\footnotetext{
Acerca de la progenie hispánica de los códigos de nuestras antiguas colonias americanas, vid.: RODRÍGUEZ ENNES, L., "García Goyena y la codificación iberoamericana", en Anuario de Historia del Derecho Español, 76, 2006, pp. 705 ss.

8 En el Reino Unido, los miembros de la alta judicatura, esto es los jueces de la Cámara de los lores, los de la Corte de Apelación y los de la High Court, gozan de un elevadísimo nivel económico-social, en correspondencia con lo que acaece en los países del Common Law; con todo, hay que precisar que los jueces norteamericanos verdaderamente asimilables a sus colegas ingleses son los federales. A mayor abundamiento, las ventajas de los jueces ingleses no se manifiestan tan sólo en el salario, sino en las condiciones de trabajo y en el brillo social que acompaña al cargo. Como con oportunidad destaca uno de nuestros más conspicuos analistas del sistema jurídico anglosajón: "Los jueces de la High Court y de la Court of Appeal adquieren automáticamente con el empleo la condición de Knights "caballeros del reino", que es el grado menor de la nobleza, de carácter vitalicio para el juez y su cónyuge -no transmisible hereditariamente- con dignidad de Sir delante del nombre y tratamiento de mylord. Los jueces de la "Cámara de los Lores " tienen completa consideración de pares del reino utilizando la distinción de Lord delante del apellido, con derecho a escudo heráldico, asiento vitalicio en la Cámara, sucesión en el título, etc. Los demás jueces -incluidos los de paz- tienen el tratamiento de your honour. Cfr. AULET BARROS, J. L., Jueces, Política y Justicia en Inglaterra y España, Barcelona, 1998, pp. 438-439.
} 
que coexista con una masiva participación popular en la administración de justicia $\mathrm{y}$, en consecuencia, se constate un mayor acercamiento al ciudadano en general, tanto por lo que atañe al seguimiento de los trámites procesales como al empleo por parte de los juristas de un lenguaje llano, inteligible, sin merma en modo alguno de la exquisita cortesía que rodea todas las actuaciones procedimentales. Así las cosas, nos proponemos partir de las referencias históricas a la multisecular separación del Antiguo Régimen entre jueces y justiciables, para centrarnos en un análisis de la situación actual - que en poco ha mejorado la anterior - efectuando una comparación con la de los países que siguen el sistema del Common Law de cuya praxis judicial es factible extraer provechosas enseñanzas para un auténtico aggiornamento de nuestro Derecho adjetivo.

\section{II}

La monarquía juega al desarraigo de los jueces, pues como oficiales reales interesa al Rey su fidelidad a las leyes y a la autoridad de aquél, tratando de que queden incontaminados de las influencias localistas 9 . Se entiende que el ser vecinos del lugar, con anterioridad a su designación, donde van a cumplir su oficio, supone el pertenecer a círculos influyentes de la localidad, con intereses creados que debilitarían su imparcialidad como jueces. Para los gobernantes y tratadistas de la época constituía una necesidad política y un imperativo ético. Como señala Molas Ribalta: "La desvinculación entre el funcionario y la sociedad que administraba era piedra angular en todo estado absoluto" 10 y apunta en otro lugar del mismo trabajo"1: "las ideas del monarca apuntaban hacia un ideal de funcionario desarraigado de la sociedad concreta que debía administrar para asegurar la imparcialidad de la justicia". El criterio de requerirse el no ser natural o vecino del lugar, se acabó imponiendo cuando la soberanía real cristalizó, aunque en mayor o menor medida y con excepciones ${ }^{12}$.

9 Amplia bibliografía en ROLDÁN VERDEJO R., Los jueces de la monarquía absoluta, La Laguna, 1989, pp. 68 ss.

${ }^{10}$ MOLAS RIBALTA, P., Consejos y Audiencias durante el reinado de Felipe II, Valladolid, 1984 pp. 107 ss.

${ }^{11}$ Ibid., p. 86. En esta misma línea, GARCÍA MARTÍN, A., La burocracia castellana bajo los Austrias, Sevilla, 1976 pp. 300-301 indica que cuando se trate de oficios del rey que se envien a ciudades y villas para representarle, no se den a los vecinos y moradores de éstos. La explicación viene de su propio peso, teniendo por un lado el riesgo de parcialidad en el desempeñom de su función en que el ministro puede incurrir frente a sus convecinos. Por otra parte, los autores resaltan la dificultad con que el morador de una ciudad o villa podrá ejercer su autoridad entre gentes de su misma patria y en muchos casos vinculados a él por lazos de diversa índole. Esta última consideración parece quedar simbolizada en la frase de Mastrillo de que cives non debent a civibus dominari.

${ }^{12}$ ROLDÁN VERDEJO, R., Los jueces de la monarquía absoluta, cit., p. 69. 
Para asegurar esa necesaria desvinculación, el magistrado, incluso foráneo, era removido al cabo de unos años de ejercicio. Los oidores y alcaldes mayores componen un personal itinerante que realiza su carrera administrativa pasando de una a otra Audiencia ${ }^{13}$. Este desarraigo, exigido por imperativo legal, se manifestaba de un modo especialmente preocupante en el caso de Galicia, cuya Audiencia ${ }^{13}$ era de las menos apetecidas y más evitadas. Alejada del polo de atracción madrileño, estaba sometida a una lejanía muy gravosa en aquellos tiempos por lo dificultoso del traslado y expuesta a los peligros de los ataques navales. Por eso poseía un Presidente militar, lo que también era motivo para no desear una plaza en ella. Contrasta abiertamente tal situación con la gran estima en que se tiene a la Audiencia de Sevilla, ubicada en una ciudad más rica, viva y alegre que A Coruña de aquellos tiempos.

A ello debemos añadir que entre los antecedentes valorados como méritos para el desempeño de cargos judiciales durante el siglo XVIII, figuraba con carácter preferente el haber sido alumno de un Colegio Mayor de las Universidades de Salamanca, Valladolid o Alcalá de Henares, reputadas como las más prestigiosas en el ámbito jurídico. Estos colegiales foráneos ocupaban luego las cátedras universitarias, los cargos judiciales y la burocracia de los Consejos ${ }^{14}$ y lo demuestra la rapidez con que avanzaban en estos ámbitos, tras la obtención de la cátedra, que les confería preferencia a la hora de ocupar vacantes en las Audiencias. Tal desarraigo, no se manifiesta sólo en la procedencia geográfica de los magistrados y en su formación académica lejos de Galicia, sino incluso en su manera de aplicar el Derecho ${ }^{15}$. Y es que los colegiales consideraban por tradición que sólo en el Derecho romano estaba la sabiduría, razón por la cual Sarmiento, con su causticidad habitual, condena abiertamente la fundación del Colegio de Bolonia porque salen juristas que vuelven a España "no a ser maestros, sino a gozar de pingües beneficios”16 y añade: “¿no ay en España derecho divino, natural y

${ }^{13}$ MOLAS RIBALTA, P., Consejos y Audiencias, cit, p. 107. En la misma línea cfr. EIRAS ROEL, A., Sobre los orígenes de la Audiencia de Galicia y sobre su función de gobierno en la época de la monarquía absoluta", en Anuario de Historia del Derecho Español, 54, 1984, p. 362.

${ }^{14}$ PESSET REIG, M., "Derecho romano y derecho real en las universidades del siglo XVIII", en Anuario de Historia del Derecho Español ,45, 1975, p. 312.

${ }^{15}$ Acerca de este peculiar modus operandi, vid.: RODRÍGUEZ ENNES L., "La ruptura del monopolio de la enseñanza del Derecho romano en las universidades españolas del siglo XVIII", en Revue Internationale des Droits de l'Antiquité, 43, Bruselas, 1996, pp. 345 ss.Traemos a colación por lo mucho que tiene de ilustrativo el testimonio de LANZ DE CASAFONDA, M.,: "Lo peor -escribe- es que para sentenciar los pleitos recurren antes al Digesto que a las Leyes de Fuero Juzgo, Partidas, Estilo, Ordenamiento y Recopilación, no teniendo los más Ministros colegiales todas estas colecciones, y muchas de ellos ni aún noticia, ni se cuidan de ello, mirándolas siempre con horror por haber sido su estudio en los colegios sobre las ápices y sutilezas del derecho civil, con que toda su vida viven preocupados". (Cfr. Diálogos de Chindulza, ed. Aguilar Piñal, Oviedo, 1972, p. 126).

${ }^{16}$ Cfr. SARMIENTO, Fr. M., Obra de Seiscientos Sesenta pliegos, v. 5, fol. 242 r., Colección Dávila, B. N. Ms. 20. 392. 
patrio? Cómo, pues, podrán faltar jurisperitos?"17, concluyendo en otro lugar: "Los comentadores españoles de leyes extrañas pudieron haberlo excusado y se debían emplear en comentar nuestras leyes patrias, utilizando los materiales que ay en los Concilios, en las leyes antiguas y en los Fueros Municipales ${ }^{18}$.

Por las razones expuestas, el lógico corolario de todo ello es que salte a la vista la escasa participación de naturales de Galicia en el elenco de magistrados que ha llegado hasta nosotros, merced a la paciente labor investigadora de Fernández Vega $^{19}$. La tendencia, tanto para la Chancillería como para las Audiencias fue teóricamente, al menos, evitar "naturales". La Provisión de 6 de enero de 1588, dada para la Cámara de Castilla, decía que se excusara buenamente "quanto se pudiere que para la Chancillería de Valladolid no se me propongan los naturales de aquel distrito, ni para la de Granada el suyo, sino por el contrario; y lo mismo se guardará en lo que toca a las Audiencias de Galicia y Sevilla, y a los corregidores y otros oficios de justicia" ${ }^{20}$. Claro que la orden no era taxativa y reconociendo las dificultades que podía ofrecer su rígida aplicación, hablaba sólo de "quanto se pudiere" y, efectivamente, no impidió que en los tribunales colegiados hubiesen jueces naturales del lugar. Pero esto no quiere decir que la regla de Felipe II se olvidase. La consulta de la Cámara de 6 de febrero de 1617, a propósito del nombramiento para la Audiencia de Galicia del gallego Arias Noguerol, señaló el problema y Arias no fue nombrado; con todo, el 12 de julio de 1563 fue también propuesto y designado el también gallego Suaces ${ }^{21}$. En las listas de magistrados destinados en Galicia se columbran muy pocos apellidos gallegos ${ }^{22}$. Con todo, en el siglo XVIII, la preferencia que se da, por encima de otras razones, a la capacidad técnica de los aspirantes fue haciendo caer en el olvido el impedimento de la vecindad ${ }^{23}$.

\footnotetext{
${ }^{17}$ Ibid., fol. 256 r. En fol. 247 r. Afirma:”Así, dirán los émulos de España, que a lo menos lograron el que los españoles hayan abandonado sus leyes patrias; para que entre ellos reine la confusión, el chisme y la discordia, con tantas leyes hermafroditas y extrañas. La que no avía, cuando sólo se juzgaba, por las solas leyes españolas, por más de mil años, asta que vino la peste de comentadores. Dirán que estos ilustran nuestras leyes patrias, con las preciosidades de Bártolo y de Baldo ¿U porqué no se ilustran nuestras leyes con otras leyes nuestras? ¿con hechos históricos nuestros? ¿Con erudición española? ¿Con señalar el origen, motivo y causa que ocasionó nuestra ley? ¿Y con una metódica análisis de toda ella? Más tiene que comentar una ley nuestra que una ley romana o imperial. Sobre estas leyes extrañas, ay millones de volúmenes corpulentísimos. Y la mayor chusma es de autores alemanes y los más clásicos son herejotazos, porque las miran como leyes propias".

${ }^{18}$ Cfr. FERNÁNDEZ VEGA, L., La Real Audiencia de Galicia órgano de gobierno en el Antiguo Régimen, III, A Coruña, 1982, pp. 419-443.

${ }^{19}$ Cfr. FERNÁNDEZ VEGA, L., La Real Audiencia de Galicia órgano de gobierno en el Antiguo Régimen, III, A Coruña, 1982, pp. 419-443..

${ }^{20}$ Nov. Recop. 4,4,1.

${ }^{21}$ FERNÁNDEZ VEGA, L., La Real Audiencia, cit., I, p. 221.

${ }^{22}$ Vid. La nt. 19.

${ }^{23}$ Acerca de la flexibilización en el siglo XVIII del principio de que los magistrados no sean naturales del mismo reino, cfr.: ARVIZU, F.,"El fiscal de la Audiencia indiana y su homónimo castellano”, en Actas
} 
En punto a la presencia de magistrados oriundos de Galicia en las Chancillerías y Audiencias de la monarquía durante el Siglo de las Luces, Eiras Roel, cotejando los datos relativos a la Audiencia de Aragón y a la Chancillería de Valladolid -únicos disponibles- encuentra numerosos nombres gallegos ${ }^{24}$. Para el ilustre profesor compostelano, los juristas gallegos seguían la carrera de la magistratura hasta sus cimas más altas, pero su proporción es inferior a la que debía corresponderles. Una decena de unos trescientos Consejeros de Castilla (el tres por ciento) equivaliendo la población de Galicia al dieciocho por ciento de la de Castilla y al doce por ciento de la de España. La mayoría de los magistrados han iniciado su carrera en algunos de los Colegios de Salamanca, Valladolid o Alcalá. Al romperse el monopolio de los seis grandes Colegios Mayores tradicionales, la situación mejora; pero en conjunto, el papel de la toga gallega es marginal y secundario dentro de los cuadros más elevados de la monarquía absoluta, a diferencia de lo que ocurrirá en la monarquía liberal del siglo XIX.

Otro de los factores de desarraigo de la magistratura en Galicia lo constituye, sin duda, el marcado carácter de Audiencia de entrada y, por tanto, de paso que, desde sus orígenes, reviste la de A Coruña. Los ya mentados inconvenientes derivados de la peligrosa ubicación de la ciudad, continuamente expuesta a las destrucciones y los expolios de los ataques navales, motivan que las vacantes sean cubiertas por jueces de nuevo ingreso que no han pasado previamente por otras Audiencias. Incluso no son infrecuentes las excusas de los nombrados para no aceptar el cargo en espera de mejor destino. En casi dos siglos -XVII y XVIII- de unos doscientos veinticinco nombrados para Galicia, sólo unos diecisiete proceden de otras Audiencias ${ }^{25}$. Incluso son varios los nombrados alcaldes mayores que no se hallan muy conformes con el destino, por entenderlo incluso como un demérito. Como dice Fernández Vega: "se dan casos en que los designados renuncian a ocupar sus puestos, suplican que no se les envie a el y no es infrecuente que los nombramientos queden sin efecto y haya que sustituirlos por sujetos más

del VI Simposium del Instituto Internacional de Historia del Derecho Indiano, Valladolid; BERMÚDEZ, A.,"Las funciones del Presidente de la Audiencia en Indias", en Memoria del IV Congreso Internacional de Historia del Derecho Indiano (México, 1976) pp. 85-96; GARCÍA GALLO, A., "Las Audiencias de Indias" cit. p. 361 ss.; KAGAN, R., "Pleitos y poder real. La Chancillería de Valladolid, 1500-1700", en Cuadernos de Investigación Histórica, $2^{a}$ ed., 1978, pp. 291-316., 1978, pp. 291-316; LALINDE, E., , La jurisdicción real inferior en Cataluña, Barcelona, 1966;MOLAS RIBALTA, P., "Las Audiencias borbónicas en la Corona de Aragón", en Historia social de la Administración española. Estudios sobre los siglos XVII y XVIII (Barcelona, 1980) p. 117-164; PÉREZ SAMPER, M. A., "La formación de la nueva Real Audiencia de Cataluña (1715-1718), en ibid. pp. 183-246; PESET, M., "La creación de la Chancillería de Valencia y su reducción a Audiencia en los años de la Nueva Planta, en Estudios de Historia de Valencia (Valencia, 1978) pp. 309-334; TUERO BERTRAND, F., La creación de la Real Audiencia en la Asturias de su tiempo (siglos XVII y XVIII) Oviedo, 1979.

${ }^{25}$ EIRAS ROEL, A.,"Prólogo" a Baudilio Barreiro, La jurisdicción de Xallas en el siglo XVIII, población, sociedad y economía, Santiago de Compostela, 1977, pp. 11-14. 
conformistas o menos influyentes", y continúa esta autora, al hablar de los casos excepcionales de traslado desde otra Audiencia más prestigiosa: “casi todos los destinos de Sevilla a Galicia traen un sello de castigo" ${ }^{\prime 26}$.

El deseo del legislador de que el juez estuviese por encima de toda sospecha de parcialidad en el desempeño del oficio llevó a aquel a invadir esferas más íntimas de su vida privada y de relación social. Se pensaba, en primer lugar, que todo arraigo en la localidad era un elemento de peligro para la integridad del juez, por los intereses creados en torno a él que podían desarrollarse. Y de ahí la prevención contra el nombramiento de "naturales", que en su momento analizamos. Pero también había prevención contra los casamientos con mujeres del lugar de destino e, incluso, con los matrimonios que pudieran celebrar los hijos del magistrado con personas de la localidad de desempeño de sus funciones ${ }^{27}$. Con todo, cumple constatar que tal prohibición no existía en Galicia ${ }^{28}$, al contrario de lo que acaecía en otras Audiencias de lugares pequeños o aislados cuyas Ordenanzas les vetaban el casamiento en el lugar ${ }^{29}$. Pero la vigilancia en torno a la vida social de los magistrados iba más allá de la mera fiscalización de los lazos matrimoniales. Las leyes fomentaban un "apartheid" social, prohibiéndoles mezclarse con la población en fiestas y diversiones, o incluso imponiendo una rigurosa abstención de visitas a personajes de la ciudad que por su cargo político o por su potencia económica pudieran, de tener litigio en la Audiencia, poner en cuestión la imparcialidad de su labor judicial. Se llegaba a los extremos de prohibir a los jueces la asistencia a espectáculos teatrales, quizás por pensar que la falta de sobriedad que concurría en ellos pudiera hacer parecer frívola la figura del magistrado, rebajando su prestancia profesional ${ }^{30}$. Con todo, debían ser

${ }^{25}$ Datos tomados de FERNÁNDEZ VEGA, La Real Audiencia, cit., I, pp. 213 ss.

${ }^{26}$ Ibidem, donde cita varios casos puntuales.

${ }^{27}$ ROLDÁN VERDEJO, R., Los jueces de la monarquía absoluta, cit., p. 323.

${ }^{28}$ FERNÁNDEZ VEGA, L., La Real Audiencia, cit., I, p. 226.

${ }^{29}$ Tal ocurría en Canarias (Ordenanzas de Peralta, 2,3,31) y, en general, en las Audiencias americanas, al estimarse muy necesario "que estén libres de parientes y deudos en aquellas partes, para que sin aficción hagan y exerzan lo que es a su cargo" (Leyes de Indias, 2,16,82).

${ }^{30}$ CASTILLO DE BOVADILLA, J., admite que el Corregidor y sus auxiliares puedan, sobre todo en los pueblos donde no hay bandos y parcialidades, tener amistad entre el vecindario, pero recela y restringe el trato frecuente con sus súbditos. Según este autor "para evitar las imparciales, querría que nuestro Corregidor evitase la mucha familiaridad y conversación con los súbditos". Con suma prudencia CASTILLO aconseja al Corregidor que "no combidasse a comer a nadie de los de su governación, ni fuese dellos combidado, pues mayor familiaridad se contrae de comer en una mesa que en sola la conversación". Y es también del parecer de que el Corregidor "no visitasse ninguno de sus súbditos... sino fuese algún titulado o persona con quien se deba cumplir... y esto muy raras vezes". Admite, sin embargo, aunque siempre con cautela, la asistencia a ciertos festejos usuales,como "quando se junta el común" o en la comida "que suelen dar los Procuradores de Cortes quando son elegidos o los Regidores cuando son admitidos", así como la asistencia a entierros de personas de calidad, cuando se le pide [Cfr. Política para Corregidores y señores de vasallos II, Amberes, 1750 pp. 204-205]. CASTILLO mantiene, en suma, una postura que poco se diferencia de la rigidez normativa. 
aficionados a las comedias los Alcaldes Mayores de Galicia, pues en las resultas de la visita de Muñoz se les reprende por haber ido, y en forma de Acuerdo, a las representaciones en el Convento de Santo Domingo ${ }^{31}$.

También se prohibía la asistencia a bodas, bautizos y otras fiestas puramente familiares $^{32}$. En este orden de cosas, las Ordenanzas de la Real Audiencia del Reyno de Galicia establecían que "Los Alcaldes Mayores... no han de visitar a ningunas personas particulares ni asistir a entierros, bodas y bautismos" ${ }^{33}$. A la vista de tamaño apartamiento social, no debe extrañarnos que en las Memorias del Arzobispado de Santiago, redactadas por el canónigo visitador Jerónimo del Hoyo se contenga una opinión muy dura sobre la gente de la Audiencia: "Tratan las cosas desde reyno con demasiada soberanía e ymperio y así se azen temer y adorar no sólo de la gente pebleya, sino de la nobleza, que con ser tan grande la deste reyno, la estiman en poco; y junto de la gente desta Audiencia con la que ay de guerra y los pleiteantes que van y vienen, y los oficiales y ministros, causa miedo a los habitantes más que si ubiera diez mil soldados en la ciudad" ${ }^{34}$.

Otro factor a tener en cuenta lo constituye la hiperinflación de las obras de los comentaristas del ius commune que, con su lenguaje farragoso y esotérico acrecentaron el divorcio entre la Universidad, la praxis forense y, lo que es peor, la sociedad $^{35}$. Ello explica que el siglo XVIII no cese de acumular escritos y peticiones de reforma, de muy diversa entidad y alcance, que no logran penetrar de todo en los densos muros universitarios. Se darán algunos pasos, siempre insuficientes para acercar la Universidad al conjunto de preocupaciones, saberes y demandas académicas de la ciudadanía. Estas mentes claras iluminadas por las "luces de la razón", no se limitaron a criticar lo caduco, sino que pretendieron reformar el sistema jurídico por el que se regía la sociedad. Como ha apuntado Tomás y Valiente, lo que intentaban conseguir era una sociedad estamental racionalizada

${ }^{31}$ Ordenanzas de la Real Audiencia del Reyno de Galicia, en lo sucesivo ORA, La Coruña, 1679, fol. 318.

${ }^{32}$ Los visitantes achacan a los magistrados de la Real Chancillería de Valladolid diversidad de distracciones que se consideran impropias; asistir en las plazas a cañas y toros; ir las mujeres a las ventanas en la fiesta del Corpus e incluso "merendando en sus ventanas con la anfitriona". Y, en general, la asidua visita a los vecinos de la ciudad "y muchas veces a personas de oficios o de calidad, o condición, de que se ha causado notable escándalo". (Cfr. Ordenanzas de la Chancillería de Valladolid, fol. 243 r.). La constante conculcación de lo ordenado demuestra que estas prohibiciones de relaciones sociales -que hoy nos parecen ingenuas- no tuvo demasiado éxito.

${ }^{33}$ ORA, $1,1,31$.

${ }^{34}$ HOYO, J., Memorias del Arzobispado de Santiago, ed. Rodríguez González y Varela Jácome, Santiago s.f., p. XIV. Para SAAVEDRA, P., "el comentario del canónigo de la Iglesia de Santiago encierra un cierto reproche, originado quizás por los enfrentamientos entre los oidores y el obispo compostelano" [Cfr. "Administración y sociedad en la Galicia del Antiguo Régimen", en Historia da Administración Pública, en lo sucesivo HAP. Santiago, 1993, p. 140).

${ }^{35}$ Acerca de las exageraciones de una enseñanza excesivamente teórica, vid.: RODRÍGUEZ ENNES, L., "Estilo de la Real Audiencia de Galicia", en Anuario de Historia del Derecho Español, 69, 1999, pp. 485-496. 
y progresiva y un Derecho adecuado a la misma, para lo cual pensaban que éste debía ser racional, uniforme y emanado de la autoridad soberana, del rey absoluto $^{36}$. No es extraño, por tanto, que la doctrina, basada en el ius commune que había constituido desde el siglo XIII el fundamento común del quehacer de los juristas y la tradición culta de la que éstos se nutrían, fuese combatida desde distintos ángulos de vista en el "Siglo de las Luces"37.

En la Ciencia del Derecho, el siglo XVIII consagra el triunfo de la doctrina del Derecho natural. Visto el papel que esta doctrina ha jugado en la Europa de las Luces, en lo que concierne a la formación de una nueva actitud con respecto al Derecho romano y sus prolongaciones en el pensamiento y en la práctica judicial, parece útil consagrarle algunas notas. Que el Derecho romano fue combatido con rigor creciente a mediad que el racionalismo crítico de la ilustración se difundió entre nosotros, está fuera de toda duda. Los juristas ilustrados tomaron aversión a unas leyes que comienzan a ser calificadas como "bárbaras" y a ser desdeñadas desde las elevadas alturas de un racionalismo seguro de su propia capacidad innovadora. Esta corriente antirromanista enlazaba con la idea del derecho popular-propia del iusnaturalismo- al exigir a las leyes una claridad y sencillez tales, que pudieran ser comprendidas por todos, sin necesidad de la intervención de los juristas ${ }^{38}$.

Podría multiplicar los textos de autores dieciochescos que destilan críticas acerbas al tremendo amasijo de comentarios, escritos de propósito en un lenguaje ríspido, que obnubilan la verdadera solución de las cuestiones prácticas abriendo, por ende, un abismo insondable entre los juristas y el común de los ciudadanos ${ }^{39}$. Las críticas al Derecho romano se entrecruzan con otras

36 TOMÁS Y VALIENTE, F., Manual de Historia del Derecho Español, $2^{\circ}$ ed., Madrid, 1980, p. 383.

37 WIEACKER, F., Privatrechtsgeschichte der Neuzeit unter besonderer Berücksichtigung der deutschen Entwicklung, $1^{\circ}$ ed., I, Göttingen, 1952, pp. 313 ss.=Historia del Derecho Privado de la Edad Moderna, trad. esp. Fernández Jardón, Madrid, 1957, pp. 197 ss.; THOMANN, J., "Influence del philosophe allemand Christian Wolff(1679-1754) sur l'Encyclopédie et la pensée plitique et juridique du XVIIIe siécle français", en Archives de Philosophie du droit, 13, 1968, pp. 234 ss., con la literatura citada en la p. 235; COING, H., "Die juristiche Fakultäten der Aufklärungszeit. Geschichte einer Studienreform", en Jahrbuch der Akademie der Wissenchaften in Göttingen, 1970, pp. 34 ss.; ID., "L'insegnamento Della giurisprudenza nell'epoca dell'Iluminismo", en L'Educazione giuridica. Il profili storici, Perugia, 1979, pp. 104 ss.

${ }^{38}$ FERNÁNDEZ BARREIRO, A., Los estudios de Derecho romano en Francia después del Código de Napoleón, Roma-Madrid, 1970, p. 18.

${ }^{39}$ Baste, a título de ejemplo, con traer a colación dos sendas opiniones muy esclarecedoras al respecto: Así Mora y Jaraba, aún cuando ataque al Derecho romano, sabe que no hay posibilidad de prescindir de sus libros: "Lo mismo debe entenderse de los papeles en Derecho y de los informes que se hacen en los Tribunales, donde se citan las leyes romanas con tal satisfacción como si fuesen preceptos del Evangelio. Cuyo abuso pudieran los jueves reformarlo fácilmente obligando a los abogados a que diesen juntamente la razón de los textos que citan; que yo aseguro que no se citarán tantos en los informes y papeles, no siendo dado a todos penetrar la razón de las Leyes Civiles, aquellas digo que están bien fundadas" (Cfr. MORA Y JARABA, P., Tratado crítico. Los errores del Derecho y abusos de la Jurisprudencia, Madrid, 1748, p. 221). En 1765 sale la primera edición de Juan Francisco de Castro, Discursos críticos sobre las leyes y sus intérpretes, donde el A. condena sin ambages al exceso en el Derecho romano como uno de 
relativas a la "imperfección" del sistema romanístico -sobre todo en su aspecto justinianeo- calificado de demasiado oscuro, lagunoso, en muchos aspectos contradictorio, cuando no indescifrable o ambiguo, frente a la imagen clara, racional, perfecta, completa de un ordenamiento jurídico fundado sobre principios jurídicos elaborados por juristas, humanistas, racionalistas, iusnaturalistas. Ya Montesquieu, en su Esprit des lois formuló esta exigencia ${ }^{40}$, reiterada entre nosotros por su riguroso contemporáneo Sarmiento ${ }^{41}$. El pensamiento de estos autores -que podemos considerar arquetípico de la época- revela una profunda desconfianza hacia el juez formado en la sutilezas romanísticas y un evidente deseo de prescindir de él ${ }^{42}$. Era necesario crear un nuevo sistema jurídico perfecto. Este sistema ideal, debería suprimir toda antinomia y toda controversia mientras que, por el contrario, el Derecho romano y sobre todo las fuentes justinianeas y el usus modernus pandectarum, dejaban el campo libre a las opiniones contradictorias y a las concepciones divergentes.

Otro factor contrario a la doctrina del viejo ius commune era intrínseco a la misma y consistía en su propia rutina. Falta de renovación, la doctrina romanista permanecía lastrada por su rancio e irreversible envejecimiento. No es de extrañar, en consecuencia, que a mediados de siglo se posea conciencia clara de que los tesoros de la interpretación jurídica se habían tornado en gruesa capa para los juristas. Los libros de los intérpretes son áridos, dificultosos de leer; las glosas o los tratados sobre una materia -en la que se entrelazan otras muchas- las decisiones

los enemigos capitales de la práctica forense: "Entre la inmensidad de leyes civiles y canónicas, entre el inexplicable número e inagotable fluxión de buenos y malos libros nacionales o extranjeros, opiniones del mismo dictado y patria, escritas y no escritas costumbres, sumergida toda humana capacidad, le han detestar una profesión en que nda hay apenas cierto y seguro, y en que el que más alcanza sólo llega, después de encontrarse en los últimos períodos de su vida, destruida su salud con tantas y tan penosas tareas, a poder más que otros por propia experiencia certificar esta verdad y asegurar lo inextricable de este laberinto" (Cfr. DE CASTRO, J. F., Discursos críticos sobre las leyes y sus intérpretes, I, Madrid, 1829, pp. III ss. Cito por esta segunda edición).

40 "Les lois ne doivente point etre subtiles: elles son faites pour des gens de médiocre entendement; elles ne sont pas un art de logique, mais la raison simple d'un pére de famille" (Cit. Por GENY, F., "La technique législative dans la codification civile moderne", en Livre dun Centenaire, II, París, 1904, p. 1006).

${ }^{41}$ Sarmiento define a la ley: “... conforme a Régla; norma justa y equi, breve, concisa, clara, en idioma vulgar, útil, necesria, que induzca y obligue in bonum, que retraiga del mal moral; constante, perpetua e inalterable". (Cfr. Obra de Seiscientos Sesenta Pliegos, cit, 5, fol. 288: Sobre el pensamiento jurídico de Fray Martín Sarmiento, vid., nuestro Fray Martín Sarmiento y el mundo del Derecho, discurso de ingreso en la Academia Gallega de Jurisprudencia y Legislación, Santiago de Compostela, 2005).

${ }^{42}$ El propio Sarmiento apunta: "Los Castellanos Antiguos tenían pocas leyes; y todos eran interesados en que se observasen; y así no tenían tanta infinidad de Hombres de Pluma, ni había tantos Pleytos" (Ibid. Fol. 2725.). También hace profesión de fe del pensamiento ciceroniano de que simplicitas legum amica: un letrado no tiene que servir para la inteligencia de la ley "pues si como es ley y justicia, que esa ley está en vulgar, clarísima, y que pueden entender todos, qualquera la entenderá. Esto se palpa en los Bandos, cuyo contexto después de Pregonado, se fixa en las esquinas. Y que son leyes, sino unos Bandos de larga duración" (Ibid. Fol. 266 v.). Los subrayados del texto son del A. 
o consejos explican oscuramente las cosas e introducen no pocos errores por la variedad de opiniones que traen; otros incluyen grandes listas de doctores para aumentar la confusión... Es un mundo extensísimo, farragoso y complicado ${ }^{43}$. Montesquieu denominaba a la compilación justinianea "El Indigesto"44. Verri escribía a propósito del ius romanum: Este amasijo de leyes, monumento de una obra mal ejecutada, puede parangonarse a las ruinas de un grande e informe palacio" ". Filanguieri-siguiendo a Leibniz- aconsejaba que fuesen quemados todos los farragosos volúmenes de estos intérpretes cuyo fanatismo "nell'ilustrazione delle leggi romane inventarono tante limitazioni, eccezioni ed amplificación, che diedero a magistrati il mezzo d'eludore il vero senso di queste leggi"46. Ya en los albores del XIX, el eximio iushistoriador Martínez Marina, escribía: “Quinientos años de experiencia nos han hecho ver claramente la imposibilidad de que los jóvenes educados en los principios del Derecho romano y familiarizados con las doctrinas de sus glosadores e intérpretes lleguen a aficionarse y mirar con gusto y menos a comprender nuestra jurisprudencia, inconciliable muchas veces con aquellos principios. Luego es necesario desterrar de los estudios generales hasta el nombre de Justiniano" 47 y ello prueba que el combate fue largo y que -del mismo modo- no emergió un claro vencedor.

\section{III}

Al observador externo siempre le ha llamado poderosamente la atención, para bien o para mal, el fuerte contenido litúrgico de que se ha rodeado desde antiguo el mundo de los tribunales para desarrollar su cometido de dispensador de la justicia. Y aunque en naciones muy próximas a la nuestra también podamos encontrar ejemplos de mundos judiciales dotados de espectaculares símbolos

${ }^{43}$ PESET REIG, M., Derecho romano y Derecho real, cit., p. 287.

${ }^{44}$ MONTESQUIEU, C. S., "Remarques sus certaines objections que m'a faites un homme qui m'a traduit mes Romains en Angleterre", en Mélanges inédits de Montesquieu, Burdeos-París, 1892, p. 205: "Il pourroit citer contre moi une infinité des lois du Code, de l'Indigeste" ¿Factura de Montesquieu o de uno de sus secretarios? Según BARCKHAUSEN, H., Montesquieu, considérations sur les causes de la grandeur des Romains et de leur décadence, ed. rev. y ajustada por ... París, 1990, p. VI fue "un secrétaire des plus ignorants, auquel Montesquieu a dicté les Remarques".

${ }^{45}$ VERRI, P., "Il café", vol. XV, en Il iluminismo giuridico. Antologia di scritti giuridici a cura di Pl. Comanduci, Bolonia, 1978, p. 121, donde añade: "Comenzaron primero Irnerio, después Acursio, Bártolo y Baldo y tantos célebres ignorantes a inundar Italia con gruesos volúmenes y, rodeados de libros de jurisprudencia nos quedamos sin leyes". Y -concluye- "Se il codice e chiaro, i commenti sono inutili o sono un abuso; s'egli e oscuro, i commenti sono tutt'al piú un remedio parziale: conviene rifonderlo, o abolirlo".

${ }^{46}$ FILANGIERI, C., "Rifflexioni politichi sull'ultima legge del nostro Sovrano, che reguarda la reforma dell'amministraziione Della giustizia", en La scienzia della legislazione e gli Opusculi scelti, V, Livorno 1826-1827, pp. 305 ss.

${ }^{47}$ MARTÍNEZ MARINA, F., cit. Por Tomás y Valiente, F., Manual, cit., p. 392. 
litúrgicos (Francia, por ejemplo), han sido precisamente los tribunales británicos los que más han destacado, por su singularidad, en estas manifestaciones formadas del ejercicio de la labor jurisdiccional ${ }^{48}$.

No se trata tan sólo de las togas, las pelucas, la sencilla belleza de sus salas de audiencia, llena de evocaciones sugerentes, sino también de sus ritos, la venerable edad de sus jueces, la atmósfera intimista y relajada, lo que separa este mundo de los otros que conocemos en el Continente. Con todo, debemos pensar que no es la toga forense o la altura de los estrados, lo que separa a los jueces y demás operadores jurídicos del justiciable sino la actitud personal de aquellos. Como en cierto modo venía sucediendo con la monarquía británica, los jueces ingleses combinan sabiamente la lejanía física y simbólica y la proximidad humana con los justiciables. Por el contrario en los países continentales el carácter de simple funcionario del juez -lejos de facilitar la comunicación con el ciudadano- es proclive al mantenimiento de ciertas connotaciones grandilocuentes ${ }^{49}$. En España, los juzgados y tribunales pasaron de ser unos lugares de nulos valores estéticos -salvo quizás el Tribunal Supremo- incluso en numerosas ocasiones merecedores del calificativo de sórdidos, hasta los modelos simples y funcionales de las nuevas construcciones. Goodrich ve en el ambiente una trasposición juicio-eucaristía porque dice: "al igual que en el sacramento eucarístico el oficiante, el sacerdote investido por Dios con poderes especialísimos para materializar el cuerpo divino en una pieza de pan y en un cáliz de vino; el juez y sus acólitos, los abogados, poseedores de un conocimiento esotérico, materializan lo que es un bien superior, la justicia, poseído por muy pocos entendidos ${ }^{50}$. Pero no es tan malo que la gente vea la representación de la auctoritas en los tribunales de justicia y sus símbolos. Más vale eso que no vean nada. Lo indeseable, en todo caso, es que no confíe en las instituciones, o que lo que contemple, cuando avada a una sala de audiencia, sea el rostro frío e inexpresivo de la burocracia.

La reinstauración del Tribunal del Jurado va a ocasionar un notable impacto sobre la situación real de la Justicia penal española y ello por razones de índole estructural dado que tenderá a reforzar la presencia del principio contradictorio y de las fases del procedimiento de estructura dialogal, de tal modo que, a largo plazo, colocará sobre el tapete la cuestión de la reforma profunda de la estructura misma del proceso penal. En todo caso, y a corto plazo, lo que sí cambiará y profundamente, es el procedimiento realmente existente, porque ante el Jurado primará la vista oral,

${ }^{48}$ AULET BARROS; J. L., Jueces, política, cit., pp. 337-338.

${ }^{49}$ BLANCO RODRÍGUEZ, L., "El empleo del lenguaje común y gestual en la justicia inglesa. Un análisis comparativo con el utilizado por la justicia española tras la instauración del jurado" en Revista Jurídica da FA7, IV, 1, abril, Fortaleza-Brasil, 2007, p. 107.

${ }^{50}$ GOODRICH, P., Languajes of Law. From Logies of Memory to Nomadic Masks. The Legal System in Ferment, I, Oxford, 1989, p. 5. 
que pasará a ser lo que legalmente es: el centro del proceso ${ }^{51}$. A su vez, el jurado dará mayor relevancia a la prueba y a su práctica en la fase oral.

Pero el Tribunal del Jurado tendrá, también, un considerable impacto sobre los usos de la Curia, por la sencilla razón de que implica una ruptura del monopolio de los profesionales del Derecho sobre el proceso penal y ello obligará a la progresiva mutación del comportamiento de fiscales, jueces y letrados, así como a una simplificación y clarificación radical del lenguaje empleado en los Tribunales $^{52}$. Estos cambios de lenguaje en el campo judicial han sido objeto de estudio, especialmente en los últimos quince años ${ }^{53}$. Genéricamente, el estudio del lenguaje pretende una mejor comprensión del proceso judicial, no siendo prácticamente un fin en sí mismo sino un instrumento de canalización. No en vano es el vehículo por el que la Ley se transmite, se interpreta y se aplica. A modo de recapitulación final sobre todo lo anteriormente expuesto, quisiera que el mundo judicial fuera consciente de los profundos cambios que se han efectuado en el lenguaje forense, motivado por la introducción del jurado. Este elemento laico, no profesional de la Administración de Justicia requiere el empleo, por parte de los letrados, fiscales y jueces, de una expresión verbal llana y sencilla, en las antípodas de los discursos esotéricos que todavía se escuchan en las Salas de Audiencia y que, a veces incluso, son de difícil comprensión para los expertos en Derecho. Claridad y comprensión constituyen, pues, los ejes en torno a los que debe gravitar toda su actuación ante el Jurado.

Otra manifestación positiva del acercamiento de la ciudadanía a los órganos jurisdiccionales, surgida al socaire de la Ley del Jurado, lo constituye sin duda, la novedosa ubicación del justiciable en las Salas de Audiencia. En efecto, a tenor del apartado $2^{\circ}$ del artículo 42 de la Ley del Jurado de 22 de mayo de 1995: "El acusado o acusador se encontrarán situados de forma que sea posible su inmediata comunicación con los defensores". Especial reconocimiento merece, por su indiscutible acierto, este precepto, carente de todo precedente concreto en nuestra legislación procesal, y que representa un importante incremento de las garantías del derecho constitucional de defensa efectiva, consagrado en el artículo 24.2 de la Constitución, estando en línea tanto con la letra o el espíritu

51 Acerca del jurado, vid., entre otros: AAVV., Comentarios a la nueva Ley de Enjuiciamiento Civil, A. Lorca Navarrete (ed.), Valladolid, 2000; ESCRIVÁ, D., El Tribunal del Jurado. Reflexiones acerca de su desarrollo constitucional, Madrid, 1988; GARCIA-GALÁN PÉREZ, A., -GARCÍA-GALÁN MOLINA, A., Formularios y comentarios de procesos civiles. Adaptados a la nueva Ley de Enjuiciamiento Civil, Madrid, 2001; HASTIE, R., La institución del jurado en los Estados Unidos: sus intimidades, Madrid, 1986; MONTERO AROCA, J., -GÓMEZ OLOMER, J. L., El nuevo proceso civil. Ley 1/2000, Madrid, 2001; MORENO CATENA, V., La nueva Ley de Enjuiciamiento Civil, IV, Madrid, 2001; SOBRAL-ARCE, G., La Psicología social en la Sala de Justicia. El jurado y el testimonio, Barcelona, 1990.

52 RODRÍGUEZ ENNES, L., "El discurso ante el jurado", en Controversia. Revista Xurídica Xeral, 4, Orense, 2003, p. 27.

${ }^{53}$ Vid., por todos, LEVI, A., Language in the Judicial Process, Nueva York, 1990. 
de las garantías recogidas en el artículo 14.3 del Pacto internacional de Derechos Civiles y Políticos suscrito en Nueva York el 16 de diciembre de 1966, con el artículo 6.3 del Convenio de Roma y con la Sentencia de nuestro Tribunal Constitucional de 3 de marzo de 1988, respecto a sus derechos "a defenderse por sí mismo y a comunicar con el defensor de su elección. Pero todavía hay algo más y que dentro de este marco de garantías constituye otra de las conquistas que la reinstauración del jurado trae a nuestro sistema de administración de justicia penal: "La muerte del banquillo". Con su supresión, de forma práctica y tangible y no meramente declarativa y programática, se verifica que el inculpado debe ser tenido por "inocente" al menos hasta que se declare su culpabilidad en virtud de sentencia firme, al punto de que -en abierto contraste con la situación anterior en que aparecía como ya condenado, sentado en el banquillo, muchas veces hasta esposado-, y ahora toma asiento en una silla digna, similar a la de su Letrado y junto a él, para poder comunicarse y consultarle, en la medida que su defensa e intereses legítimos lo requieran; asimismo en coherencia con los postulados del artículo 11.1 de la Declaración Universal de los Derechos Humanos de 1948. Lástima es tener que constar que tamaño progreso haya quedado constreñido a los juicios con jurado, desaprovechando una vez más el magnífico ejemplo que -a este respecto- nos ofrece la experiencia judicial anglosajona.

Y ya para finalizar, quisiera referirme a la infrautilización que tiene lugar en España del otro elemento participativo del común de los ciudadanos en la Administración de Justicia: los jueces legos. Frente a una justicia de paz como la inglesa, que supone una amplísima intervención del elemento lego en los órganos jurisdiccionales, la justicia de paz continental o bien aparece como algo insignificante, o, simplemente, no existe en absoluto. La competencia en materia criminal de los juzgados de paz ingleses es siempre de primera instancia, y para valorar su peso en el sistema criminal baste decir que en ellos se juzga entre el 96 y el $98 \%$ de la totalidad de los juicios criminales del país ${ }^{54}$. En cualquier caso, todos los juicios criminales han de empezar en el juzgado de paz, puesto que no existiendo en Inglaterra nada equivalente a la instrucción criminal, era necesario dotar al sistema de un control judicial que impidiese llevar a juicio a una persona sin contar con una mínima base probatoria. Los jueces de paz gozan de poderes amplios y flexibles en materia criminal. Pueden condenar a penas de privación de libertad hasta seis meses (y si juzgan de delitos conexos, hasta doce meses en total) e imponer multas de hasta cinco mil libras. En España, por el contrario, aunque la justicia de paz sobrevivirá al período constituyente, bien que reducida

${ }^{54}$ AULET BARROS, J. L., Jueces, política, cit., pp. 551-552. 
como en las últimas décadas a la "mínima expresión"; expresión que cabe calificar sin ambages de puramente simbólica: faltas nimias en el ámbito punitivo y pleitos civiles de cuantía irrisoria. Como consecuencia, y a pesar de posibles entusiasmos que pueda generar la presencia de jueces legos en la administración de justicia española por la apariencia democratizadora que da al sistema ${ }^{55}$, mucho nos tememos que nada aportan en su actual configuración a la democracia y popularidad del sistema político.

${ }^{55}$ Con todo, cabe poner de manifiesto la existencia en España, dentro de sectores de la judicatura y de la doctrina procesalista, de defensores de lo que denominan "justicia de proximidad" y que trata de incorporar a nuestro ordenamiento la experiencia jurídica anglosajona. Vid., por todos, BANDRÉS, J. M., "El desafío democrático de la justicia de proximidad", en Jueces para la Democracia, 48, 2003, pp. 88- 